\title{
CIRUJANOS OCULISTAS EN LA GACETA DE MADRID (S. XVIII) (I)
}

\author{
LÓPEZ DE LETONA C ${ }^{1}$
}

La Gaceta de Madrid fue un periódico que comenzó a editarse en la capital de España durante las últimas décadas del siglo XVII y que alcanzó mayor difusión durante la centuria siguiente al tener lugar el advenimiento de la nueva dinastia borbónica que como es sabido sucedio a los Austrias.

La publicación gozaba de protección real y era en cierto modo el antecedente del actual Boletín Oficial del Estado, se dedicaba sobre todo a recoger noticias de hechos que sucedían en Madrid incluyendo lo referente a la casa Real, enfermedades de los reyes o sus hijos, defunciones,... etc.

Pero existe un aspecto que nos interesa particularmente, nos referimos a aquellas informaciones que hacen referencia a cirujanos oculistas que ejercían su oficio no sólo en la capital del reino sino también en otras ciudades incluso en pequeñas poblaciones.

Hemos repetido en numerosas ocasiones que los cirujanos no eran en realidad médicos, su formación resultaba mucho más precaria que éstos y estaban socialmente considerados por debajo de los médicos, la Oftalmología estuvo durante mucho tiempo en manos de estas personas, curaban diversas afecciones oculares con especial dedicacion a las cataratas.

Nos proponemos en este artículo y en el siguiente ofrecer algunas notas interesantes a este respecto que hemos entresacado de la lectura de algunos trabajos basados en el estudio minucioso de los contenidos de dicha Gaceta

El primer profesional con el que nos encontramos fue Pedro Aguilar, el cual fue cirujano oculista del Hospital General de Madrid.

Ya en el Siglo XVIII se habian refundido muchos de los pequeños hospitales existentes, algunos de ellos dependientes de cofradias o de la generosidad de particulares. El Hospital General es en cierta manera antecesor de los modernos Hospitales Clinicos.
Pedro Aguilar intervino en 1799 en una curiosa curación de una oftalamopatía por medio de la electricidad, que acababa de descubirse, lo que implicaba una gran novedad.

La Junta General del Hospital había mandado construir cuatro años antes «Dos máquinas eléctricas» que utilizaban en casos concretos, uno de ellos debió ser el nuestro.se trataba de un paciente del que nos ha llegado el nombre: Santiago Fernández, tenia «Temperamento irascible» y era curtidor en la localidad de Aravaca.

Había sido acogido en el Hospital en Agosto de 1799 por padecer una «Gota serena», nos hemos encontrado muchas veces con este término, se refiere a una ceguera de origen más o menos desconocido.

A nuestro paciente se le administraron «Los remedios usuales» en esta afeccion pero al parecer sin exito, por ello «Se pasó a la electricidad», verificandose «La electrificacion por baño» durante media hora por espacio de una semana utilizando la referida máquina de la que nuestra fuente no ofrece más noticias, habla eso sí, de un disco de cristal que se aplicaba en la órbita del enfermo, acaso nos encontremos ante un aparato de diatermia, pero todo esto son suposiciones.

Las vicisitudes del caso son importantes ya que hubo que suspender en varias ocasiones el tratamiento por presentar el paciente fuertes cefaleas que le duraron tres dias, y a causa de otra indisposición parecida no se aplicó la electricidad durante al menos once dias .

Fue entonces cuando recurrieron a las sanguijuelas y posteriormente de nuevo a la electricidad.

Lo curioso del caso es que segun nuestra fuente el paciente «Salió de este Hospital curado a satisfación de D Pedro Aguilar».

Hay otro cirujano oculista del que querriamos dar noticias, es Pedro Antonio Colomer que vivía en Madrid.

\footnotetext{
1 IOBA. Valladolid. España.

E-mail: berta@ioba.med.uva.es
} 
A comienzos de 1794 se nos informa que ha operado de cataratas a dos pacientes: un religioso Fray Joseph Alexo de 87 años y otra persona de parecida edad: vecino de Fuenlabrada era D. Agustín de la Pesca.

Las noticias de este oculista continúan siendo variadas porque más adelante se nos refiere que solo cura las referidas cataratas, diciendonos incluso que ha ideado un instrumento al respecto, de modo que las interviene en un espacio de tiempo de uno o dos minutos sin que la persona operada sufra lo más minimo.

Pero no nos dice si interviene por uno de los dos métodos conocidos: el abatimiento o la extracción, entre los tratados figura un D. Diego Perelló «Del consejo de $\mathrm{Su}$ Majestad», acaso se tratase de un abogado distinguido.
En 1797, como harían otros profesionales incluso hasta tiempos persentes nuestro cirujano se desplaza a Valencia a instancias de D. Francisco Gabarrot, al que ya había operado de otra catarata el año anterior. Aquí si que se nos refiere que fue mediante la extracción.

No queremos finalizar este primer artículo sin dar al menos los nombres de otros dos oculistas: Benito Dorado y Juan Pascual Sala.

El primero ejerce en Fresnillo de las Dueñas (Toledo) y había conseguido ser muy diestro en la extracción de la catarata, incluso en pacientes de edad avanzada.

Jaun Pascual Sala trabajaba en la localidad extremeña de Membrio y es cirujano «Aprobado», conoce ambos métodos de curacion de las cataratas. 